\title{
Positive Thinking Can Change Our Life
}

\author{
Sonal D. Parmar ${ }^{1}$
}

\section{ABSTRACT:}

Our mind is a thought factory. It is a busy factory, producing countless thoughts in one day. There are two main ways of thinking; Thinking positively and thinking negatively. Over the year's lot of research done on the positive effects of being positive and the negative effects of being negative. The research is clear. Being positive is not just a nice way to live. It's the way to live. A positive thinking helps you cope more easily with the daily affairs of life. It brings optimism into your life, and to avoid worries and negative thinking. Negative thinking, for a start, makes you feel bad in the present. So it is better to think positively instead of think negatively.

Keywords: Positive, Negative, and Thinking.

"There is little difference in people, but that little difference makes a big difference. The little difference is attitude. The big difference is whether it is positive or negative."

Learn more below about the effects of negative thinking versus positive thinking. Why? Because the type of thoughts that you choose to focus on will shape your reality. They learn to notice their thoughts. Are you a positive person? Read the following descriptions of negative thinking versus positive thinking and find out not only where you are, but also where you can be. Thinking plays a very important role in our everyday life. Every action is accompanied by a thought.

Much of your behavior depends on your attitudes. If your attitudes are negative, you can expect to be vulnerable to addictions and psychosomatic disorders, and the resulting lack of focus and concentration may degrade every area of your life. A positive attitude can be developed by monitoring and disciplining your thoughts on a moment-by-moment basis

There are two main ways of thinking; Thinking positively and thinking negatively. For a pessimist, there is always something to worry about, nothing is ever quite right, bad events seem to last forever, and they outweigh the positive ones. Life means living in fear, sadness or anger most of the time.

\footnotetext{
${ }^{1}$ Research scholar, M.A., B.Ed, M.Phil, G-SET) Department of Psychology Saurashtra University
} 
An optimist is someone who generally keeps a positive attitude, has a good mood, and tends to look for the silver lining of apparent difficulties or negative circumstances. Optimists don't dwell on worries. If they feel defeated, they also feel it's temporary. They usually also choose to accentuate the positive.

Negative thinking, for a start, makes you feel bad in the present. One of the most common displays of negative thinking fears an event in the future - something that perhaps will never happen. Frankly speaking thinking positively is much better for yourself and your surroundings. Any negative thought can have terrible consequences. Jealousy is an imperfection that man has a role to play in the creation of negative thinking.

Thinking positively shows that there is a mutual respect between two people. A positive attitude helps you cope more easily with the daily affairs of life. It brings optimism into your life, and to avoid worries and negative thinking.

With a positive attitude you see the bright side of life, become optimistic, and expect the best to happen. When we allow ourselves to think negatively we limit our potential in many ways. The worst thing is that we may be so wrapped in negativity that we cannot even see that there are ways out. However, there is always a choice. The key is your awareness of your own thoughts; then you can decide which type of thoughts you want to focus on.

\section{HOW TO DEVELOPING A POSITIVE ATTITUDE?}

Learn more below positive thinking

1. Choose to be happy.

2. When negative thoughts enter your mind, just refuse to look at them, doing your best to substitute them with happy thoughts

3. Look at the bright side of life

4. Choose to be optimistic.

5. Find reasons to smile more often

6. Have faith in yourself, and believe that the Universe can help you.

7. Associate yourself with happy people.

8. Read inspiring stories, inspiring quotes.

"Negative attitude says: you cannot achieve success".

"Positive attitude says: You can achieve success". 
Positive attitude depends on this following ways:

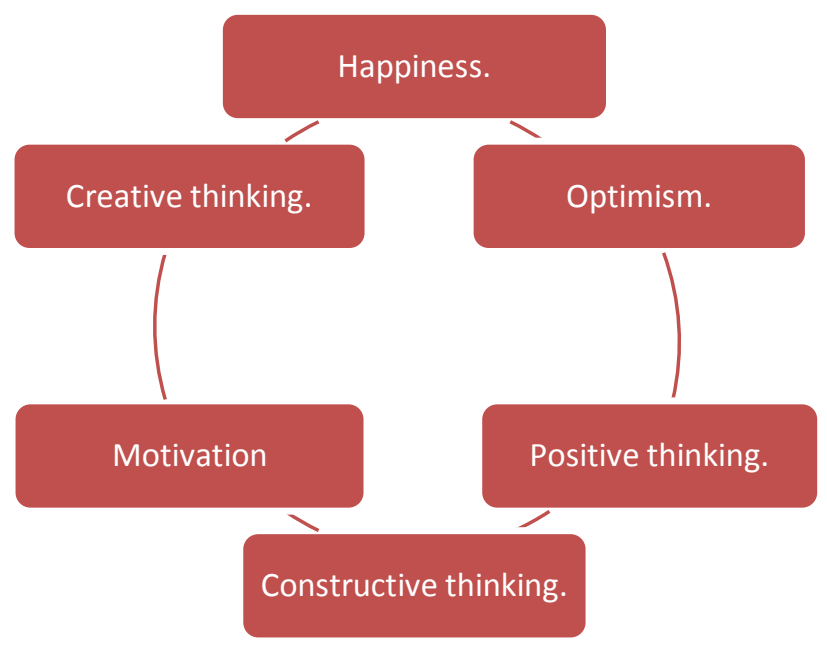

Over the year's lot of research done on the positive effects of being positive and the negative effects of being negative. The research is clear. Being positive is not just a nice way to live. It's the way to live. Here is advantage of positivity.

\section{ADVANTAGES OF POSITIVITY}

1. Expecting success and not failure.

2. It helps you achieve goals and attain success.

3. It brings more happiness into your life.

4. It produces more energy.

5. Positive attitude increases your faith in your abilities, and brings hope for a brighter future.

6. You become able to inspire and motivate yourself and others.

7. You encounter fewer obstacles and difficulties in your daily life.

8. You get more respect and love from people.

9. Life smiles at you.

10. Making you feel inspired.

11. It gives you the strength not to give up, if you encounter obstacles on your way.

12. It makes you look at failure and problems as blessings in disguise.

13. Believing in yourself and in your abilities.

14. Enables you to show self-esteem and confidence.

15. You look for solutions, instead of dwelling on problems.

16. You see and recognize opportunities. 
A positive attitude leads to happiness and success and can change your whole life. This light affects not only you and the way you look at the world, but it also affects your environment and the people around you.

\section{CONCLUSION:}

Thus we know two kind of thinking or thoughts first one is positive and the second one is negative. With a positive attitude/thinking we see the bright side of life, become optimistic, and expect the best to happen. When we allow ourselves to think negatively we limit our potential in many ways. A positive attitude helps you cope more easily with the daily affairs of life. It brings optimism into your life, and to avoid worries and negative thinking. Negative thinking, for a start, makes you feel bad in the present. So it is better to think positively instead of think negatively.

\section{REFERENCES}

1. http://www.livestrong.com/article/120699-negative-thinking-vs.-positivethinking/

2. http://www.the-benefits-of-positive-thinkingcom/negative-thinking-versuspositivethinking.html

3. http://www.pickthbraincom/blog/positivity-vs-negativity-question-focus/

4. http://www.mintools.com/pages/article/newTCS_89.htm

5. http://www.livestrong.com/article/14056positive-attitude-vs-negativeattitude/

6. http://www.livestrong.com/article/12069-negative-thinking-vs.-positive-thinking/

7. http://www.succeconsciousness.com/positive_attitude.htm

8. http://www.jongrdon.com/blog/11-benefits-of-being-positive-3/

9. http://www.123helpme.com/search.asp?text=positivetyandbenifits\&sort=relevancemode= TEXT

10. http://www.pickthebrain.com/blog/positivity-vs-negativity-question-focus/ 